\title{
Excitation of Highly Conjugated (Porphinato)palladium(II) and (Porphinato)platinum(II) Oligomers Produces Long-Lived, Triplet States at Unit Quantum Yield That Absorb Strongly over Broad Spectral Domains of the NIR ${ }^{\dagger}$
}

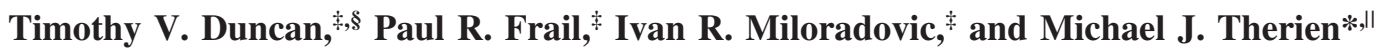 \\ Department of Chemistry, University of Pennsylvania, Philadelphia, Pennsylvania 19104-6323, and \\ Department of Chemistry, French Family Science Center, Duke University, Durham, \\ North Carolina 27708-0354
}

Received: March 31, 2010; Revised Manuscript Received: May 7, 2010

\begin{abstract}
Transient dynamical studies of bis[(5,5'-10,20-bis(2,6-bis(3,3-dimethylbutoxy)phenyl)porphinato)palladium(II)] ethyne (PPd $)$, 5,15-bis $\left\{\left[\left(5^{\prime}\right.\right.\right.$-10,20-bis(2,6-bis(3,3-dimethylbutoxy)phenyl)porphinato)palladium(II)]ethynyl $\}(10,20$ bis(2,6-bis(3,3-dimethylbutoxy)phenyl)porphinato)palladium(II) (PPd $)$, bis[(5,5'-10,20-bis(2,6-bis(3,3-dimethylbutoxy)phenyl)porphinato)platinum(II)]ethyne (PPt ${ }_{2}$ ), and 5,15-bis $\left\{\left[5^{\prime}-10,20\right.\right.$-bis(2,6-bis(3,3-dimethylbutoxy)phenyl)porphinato)platinum(II)] ethynyl $\}$ (10,20-bis(2,6-bis(3,3-dimethylbutoxy)phenyl)porphinato)platinum(II) (PPt $\mathbf{3}_{3}$ show that the electronically excited triplet states of these highly conjugated supermolecular chromophores can be produced at unit quantum yield via fast $\mathrm{S}_{1} \rightarrow \mathrm{T}_{1}$ intersystem crossing dynamics $\left(\tau_{\text {isc: }}: 5.2-49.4 \mathrm{ps}\right)$. These species manifest high oscillator strength $\mathrm{T}_{1} \rightarrow \mathrm{T}_{n}$ transitions over broad NIR spectral windows. The facts that (i) the electronically excited triplet lifetimes of these $\mathbf{P P d}{ }_{n}$ and $\mathbf{P P t}{ }_{n}$ chromophores are long, ranging from 5 to $50 \mu \mathrm{s}$, and (ii) the ground and electronically excited absorptive manifolds of these multipigment ensembles can be extensively modulated over broad spectral domains indicate that these structures define a new precedent for conjugated materials featuring low-lying $\pi-\pi^{*}$ electronically excited states for NIR optical limiting and related long-wavelength nonlinear optical (NLO) applications.
\end{abstract}

\section{Introduction}

Organic materials that can attenuate the intensity of sudden strong pulses of light are an important means to protect sensitive optical devices. There is keen interest in the development of optical power limiting (OPL) materials that function over the $750-1600 \mathrm{~nm}$ spectral regime of the near-infrared (NIR), as this wavelength domain encompasses the primary emission lines of a variety of important lasing media (Ti:sapphire, Nd:YAG, Nd:YLF, GaAs, GaAlAs, InGaAs, krypton, HeNe, argon, Cr: Forsterite, and Er:glass), as well as the important telecommunication wavelengths. While there are many physical mechanisms that can give rise to OPL, one of the most important is reverse saturable absorption (RSA) ${ }^{1,2}$ Materials exhibiting RSA possess strong excited-state absorptive cross sections and weak ground-state absorptive intensity over the spectral window of interest for optical limiting. The additional requirements of a long excited-state lifetime, high resistance to degradative photochemistry, and large magnitude nonlinear optical (NLO) response have made identification of OPL candidates based on RSA for the NIR difficult. In contrast, a wide variety of optical limiting materials based upon phthalocyanine, ${ }^{3-11}$ porphyrin, ${ }^{12-14}$ fullerene, ${ }^{15-20}$ carbon nanotube, ${ }^{9,21-25}$ nanoparticle, ${ }^{26-34}$ and other ${ }^{35-40}$ motifs have been identified for the visible spectral region. The limited number of potential NIR OPL materials ${ }^{39,41-48}$ elucidated to date derives largely from the fact that most compounds that possess excited states that absorb strongly in

\footnotetext{
Part of the "Michael R. Wasielewski Festschrift".

* To whom correspondence may be sent. E-mail: michael.therien@ duke.edu.

* University of Pennsylvania.

$\S$ Current affiliation: U.S. Food and Drug Administration, Summit-Argo, IL 60502.

"Duke University.
}

the NIR also manifest diminished excited-state lifetimes due to increased rates of nonradiative relaxation from their respective low-lying excited electronic states. ${ }^{49-51}$

The simultaneous requirements of a long $(>\mu \mathrm{s})$ excited-state lifetime, substantial photostability, and broad, high oscillator strength excited-state absorptivity in the NIR, have led to the development of supermolecular chromophores that manifest coupled-oscillator photophysics and extensively delocalized low energy excited triplet $\left(T_{1}\right)$ states characterized by substantial charge-separated (CS) character. ${ }^{52,53}$ While these highly conjugated charge-transfer chromophores define new benchmarks for NIR optical limiting, ${ }^{52,53}$ it remains an open question whether conjugated materials that feature low-lying electronically excited states that are predominantly $\pi-\pi^{*}$ in nature can manifest similar $\mathrm{T}_{1}$-state lifetimes and NIR absorptive characteristics. We report herein highly conjugated palladium(II)- $\left(\mathbf{P P d}_{n}\right)$ and platinum(II)-containing $\left(\mathbf{P P t} \mathbf{P}_{n}\right)$ porphyrin arrays (Chart 1) that exhibit near-unity $S_{1} \rightarrow T_{1}$ intersystem crossing (ISC) quantum yields, $\mathrm{T}_{1}$-state lifetimes that exceed $1 \mu \mathrm{s}$, and high oscillator strength $\mathrm{T}_{1} \rightarrow \mathrm{T}_{n}$ absorptive manifolds that extend over a broad $850-1350 \mathrm{~nm}$ spectral window.

\section{Experimental Section}

Synthesis and Characterization. A full account of the synthesis and characterization of all new compounds, complete with detailed reaction schemes, is provided in the Supporting Information.

Instrumentation. Electronic spectra were recorded on a Shimadzu UV-1700 spectrophotometer. Emission spectra were recorded on a SPEX Fluorolog luminescence spectrometer that utilized a T-channel configuration and R2658 PMT (200-900 $\mathrm{nm}) /$ Electro-Optical Systems, Inc. and DSS-16AO20L InGaAs 
CHART 1: Structures of Bis- and Tris(porphinato)metal(II) Arrays $\mathbf{P Z n}_{n}, \mathbf{P P d}_{n}$, and $\mathbf{P P t}_{n}$ $(n=2,3)$

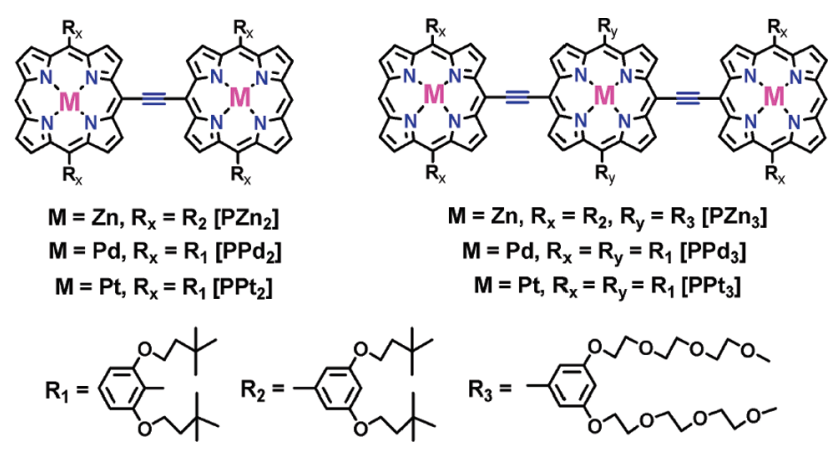

$(800-1200 \mathrm{~nm})$ detectors; these spectra were corrected using the spectral output of a calibrated light source. Low temperature (77 K) spectra were determined using an optical dewar. NMR spectra were recorded on $250 \mathrm{MHz}$ AMX-250 or $500 \mathrm{MHz}$ AMX-500 Brüker spectrometers. Microwave reactions were performed using a Personal Chemistry Creator (now Biotage) utilizing custom glass reaction vessels.

Transient Absorption Spectroscopy. The femtosecond ${ }^{54}$ and nanosecond ${ }^{55}$ transient optical systems used for the experiments in this work have been described previously. All samples that were interrogated via transient pump-probe spectroscopic methods were deoxygenated via three successive freeze-pumpthaw cycles prior to measurement.

X-ray Crystal Structures. Dr. Patrick J. Carroll of the X-ray diffraction facility at the University of Pennsylvania solved the structures for compounds described in this work. $\mathbf{P P d}_{\mathbf{2}}$ and $\mathbf{P P t}_{\mathbf{2}}$ crystals were grown from dichloromethane solution layered with methanol. The two solvents slowly diffused followed by slow evaporation. X-ray quality crystals were grown after 2 weeks. A full description of the details and results of these structure determinations is provided in the Supporting Information.

Electrochemistry. Cyclic and square wave voltammetry were carried out on an EG\&G Princeton Applied Research model 273A potentiostat/galvanostat. The electrochemical cell utilized a glassy carbon disk working electrode, a platinum wire counter electrode, and a saturated calomel reference electrode (SCE). The reference electrode was separated from the bulk solution by a junction bridge filled with the corresponding solvent/ supporting electrolyte solution. The ferrocene/ferrocenium redox couple was utilized as an internal potentiometric standard.

\section{Results and Discussion}

The highly conjugated palladium(II)- $\left(\mathbf{P P d}_{n}\right)$ and platinum(II)containing $\left(\mathbf{P P t}_{n}\right)$ porphyrin arrays described in Chart 1 feature a meso-to-meso ethyne-bridged linkage topology; a large body of experimental data demonstrates that the strong electronic coupling mediated by this multiporphyrin linkage motif creates unusually polarizable and hyperpolarizable structures. ${ }^{53,54,56-79}$ The syntheses of $\mathbf{P P d} \mathbf{P}_{2}, \mathbf{P P d}, \mathbf{P P t}$, and $\mathbf{P P t} \mathbf{t}_{3}$ were accomplished through metal-mediated cross-coupling of appropriately brominated and meso-ethyne-functionalized (porphinato)zinc(II) precursors. ${ }^{57,63,80,81}$ Scheme 1 highlights the synthetic route to the $\mathbf{P P d} \mathbf{d}_{2}$ and $\mathbf{P P t}_{2}$ structures, while the analogous path to the $\mathbf{P P d}_{3}$ and $\mathbf{P P t}_{3}$ species is shown in Scheme S1 of the Supporting Information. Following the syntheses of the parent $\mathbf{P Z \mathbf { n } _ { 2 }}$ and $\mathbf{P Z n}_{3}$ complexes, these species were demetalated to generate the corresponding free-base complexes $\left(\mathbf{P F b}{ }_{n}\right)$. $\mathbf{P P d}$ and $\mathbf{P P t}_{n}$ complexes were synthesized in high yield from their corre- sponding $\mathbf{P F b}_{n}$ precursors via microwave-assisted synthesis (Supporting Information).

Previous work has demonstrated that $\mathbf{P Z n} \mathbf{n}_{n}$ conjugated porphyrin arrays manifest low energy Q-state derived $\pi-\pi^{*}$ excited states that are polarized exclusively along the respective long molecular axes. ${ }^{53,54,56,57,59,63,66,69,72,75}$ The lowest energy optical transitions of these species gain in intensity and shift progressively to the red with increasing numbers of conjugated porphyrin units. The electronic absorption spectral data acquired for $\mathbf{P P d} \mathbf{P}_{2}, \mathbf{P P d} \mathbf{d}_{3}, \mathbf{P P t}$, and $\mathbf{P P t} \mathbf{3}_{\mathbf{3}}$ (Figure 1, Table 1) manifest the general spectroscopic characteristics delineated previously for the corresponding $\mathbf{P Z n _ { 2 }}$ and $\mathbf{P Z n}_{\mathbf{3}}$ benchmarks. Note that all of the $\mathbf{P P d}{ }_{n}$ and $\mathbf{P P t}_{n}$ species display high oscillator strength Q-state derived low energy $\pi-\pi^{*}$ absorption bands, with a molar extinction coefficient exceeding $65000 \mathrm{M}^{-1} \mathrm{~cm}^{-1}$ for $\mathbf{P P t}_{3}$. The spectra in Figure 1 demonstrate that compared to the analogous $\mathbf{P Z n} \mathbf{n}_{n}$ spectroscopic benchmarks, the Q-state derived electronic absorption bands for the palladium and platinum derivatives are blue-shifted; this phenomenon is common to hypsoporphyrin species and has been attributed to efficient mixing of the porphyrin $\pi^{*}$ and metal $n d_{\pi}$ orbitals. ${ }^{82-84}$ Furthermore, X-ray crystallographic data (Supporting Information) show that $\mathbf{P P d} \mathbf{P}_{\mathbf{2}}$ and $\mathbf{P} \mathbf{P t}_{\mathbf{2}}$ access not only conformations in which the adjacent porphyrin least-squares planes do not share a common plane but also those where the $\mathrm{C}_{\text {meso }}-\mathrm{C}_{\alpha \text {-ethyne }}-$ $\mathrm{C}_{\beta \text {-ethyne }}$ angle deviates significantly from $180^{\circ}\left(\mathbf{P P d}_{2}=173.8^{\circ}\right.$; $\mathbf{P P t}_{2}=172.0^{\circ}$ ); it is well established within this class of chromophores ${ }^{54,59,66}$ that such structural conformers augment the magnitude of $\mathrm{Q}_{x}$-state absorption oscillator strength that is blueshifted with respect to that which corresponds to the maximally conjugated conformer.

Emission spectra recorded at $77 \mathrm{~K}$ in glassy 2-methyltetrahydrofuran (MTHF) solvent for $\mathbf{P P d}{ }_{n}$ and $\mathbf{P P t} t_{n}$, as well as for the $\mathbf{P Z \mathbf { n } _ { n }}$ benchmarks, are depicted in the Figure 1 insets. The palladium and platinum species manifest well-resolved phosphorescence $\left(\mathrm{T}_{1} \rightarrow \mathrm{S}_{0}\right)$ transitions at $77 \mathrm{~K}$, approximately $3000 \mathrm{~cm}^{-1}$ red-shifted from their respective lowest-energy ground-state singlet absorption band maxima; note that these chromophores contrast their respective zinc analogues, which exhibit no observable phosphorescence, even at $77 \mathrm{~K} .{ }^{54,58}$ The observed phosphorescence in the palladium and platinum compounds derives in part from the efficient $\mathrm{S}_{1} \rightarrow \mathrm{T}_{1}$ intersystem crossing (ISC) facilitated by the large spin-orbit coupling constants of these heavy central metal ions. ${ }^{51,84}$ It is important to note, however, that even at $77 \mathrm{~K}$, phosphorescence for $\mathbf{P P d}_{n}$ and $\mathbf{P P t}{ }_{n}$ is weak (phosphorescence quantum yields, $\phi_{\mathrm{p}}$, were estimated by comparison to fluorescent (porphinato)zinc benchmarks to be below 5\%). Note also that $\mathbf{P P d}$ and $\mathbf{P P t}_{3}$ also exhibit residual fluorescence $\left(\mathrm{S}_{1} \rightarrow \mathrm{S}_{0}\right)$ bands (Table 1); excitation spectra evince that this fluorescence is authentic and does not derive from residual free-base impurities.

Pump-probe femtosecond transient absorption spectroscopy was employed to investigate the absorptive properties and relaxation dynamics of the $\mathbf{P} \mathbf{P d}_{n}$ and $\mathbf{P P t}_{n}$ excited states. Representative transient absorption spectra recorded at various time delays are shown in Figure $2\left(\mathbf{P P d}_{2}, \mathbf{P P t}_{2}\right)$ and Figure 3 $\left(\mathbf{P P d}_{3}, \mathbf{P P t}_{3}\right)$, along with the analogous dynamical data obtained for the corresponding $\mathbf{P Z n} \mathbf{n}_{n}$ benchmarks. ${ }^{54,66}$ The early timedelay transient absorption spectra $\left(t_{\text {delay }}<500 \mathrm{fs}\right.$, Figures 2 and 3, black lines) of each $\mathbf{P Z n}_{n}, \mathbf{P P d}_{n}$, and $\mathbf{P P t}_{n}$ chromophore share several common features: (a) bleaching signatures of the groundstate Q- and B-state derived bands, (b) transient absorption in the spectral region between these two bleaching signatures, and (c) intense excited-state absorption manifolds that extend over 
SCHEME 1: Synthetic Reaction Scheme for $\mathbf{P Z n}_{2}, \mathbf{P P d}_{2}$, and $\mathbf{P P t}_{2}{ }^{a}$
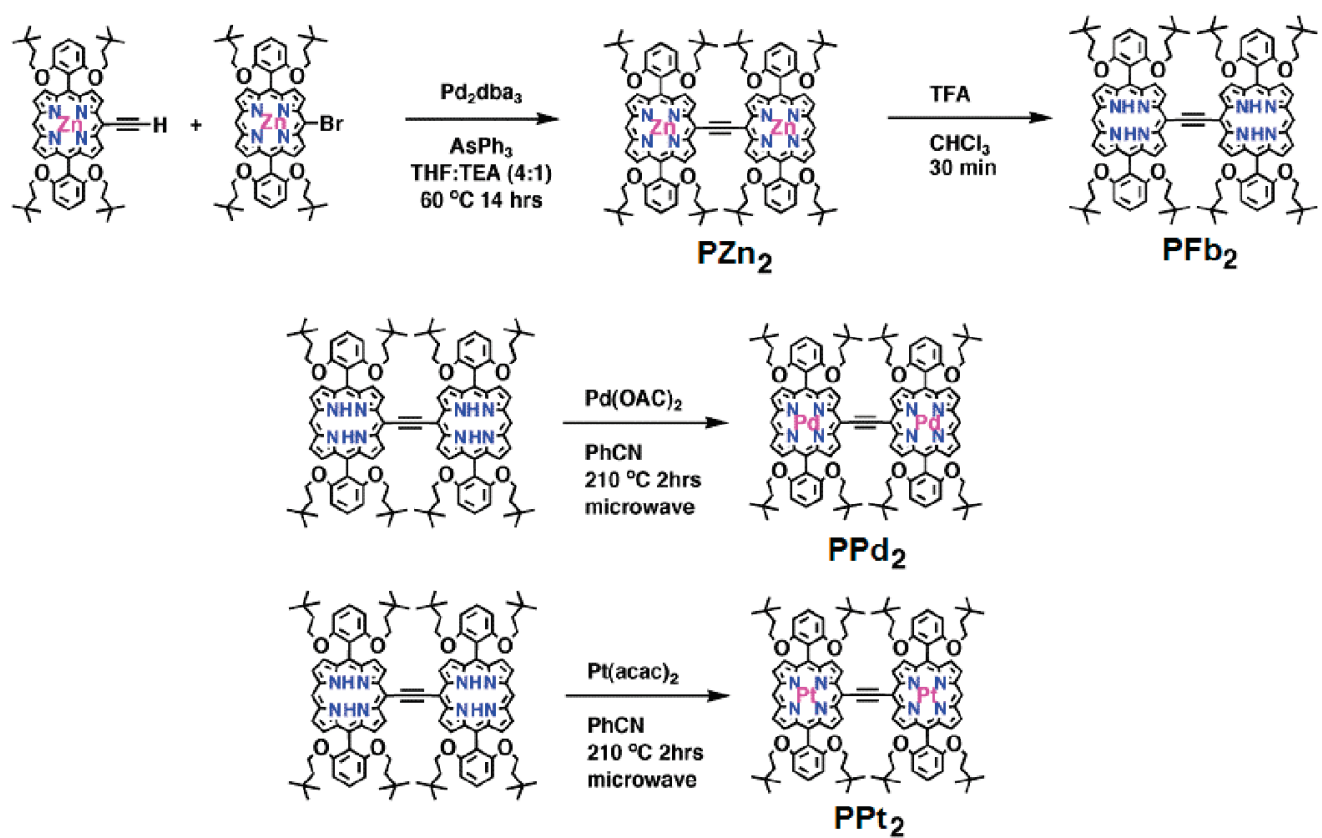

${ }^{a}$ Detailed synthetic procedures for these species, as well as for the corresponding trimeric $\mathbf{P Z} \mathbf{n}_{\mathbf{3}}, \mathbf{P P d _ { 3 }}$, and $\mathbf{P P t} \mathbf{P}_{\mathbf{3}}$ structures, are provided in the Supporting Information.

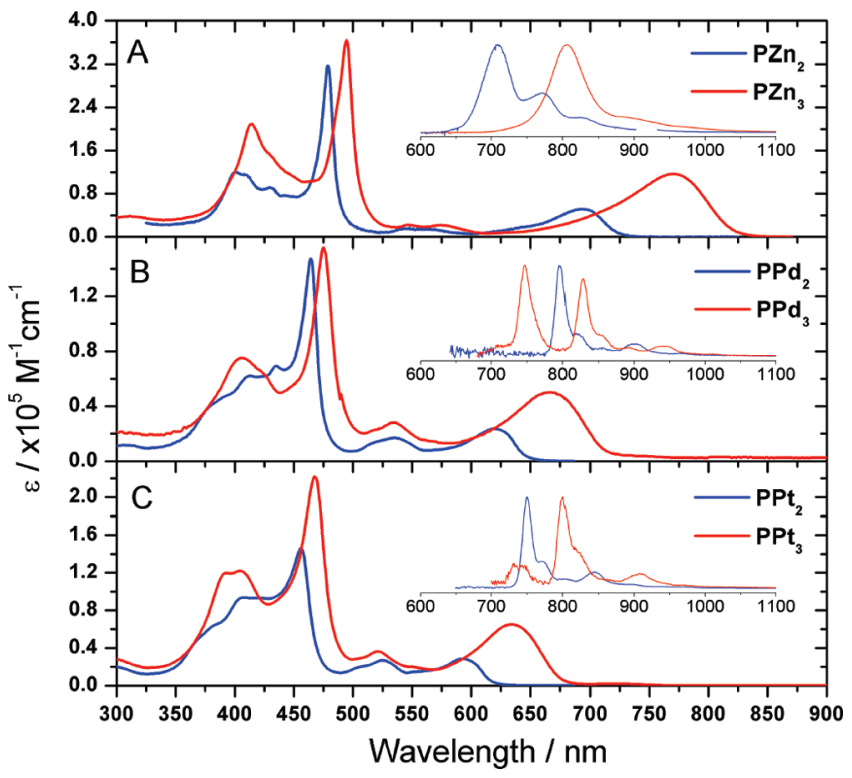

Figure 1. Electronic absorption spectra recorded for (A) $\mathbf{P Z n} \mathbf{n}_{n}{ }^{63}$ (B) $\mathbf{P P d}_{n}$, and (C) $\mathbf{P P t}_{n}$ in THF solvent at ambient temperature $[n=2$ (blue); $n=3$ (red)]. Insets: normalized emission spectra, recorded in deoxygenated glassy MTHF at $77 \mathrm{~K}$. Excitation wavelengths: (A) 460 $\mathrm{nm}\left(\mathbf{P Z n}_{n}\right)$, (B) $630 \mathrm{~nm}\left(\mathbf{P P d}_{2}\right), 650 \mathrm{~nm}\left(\mathbf{P P d}_{3}\right)$, and (C) $600 \mathrm{~nm}\left(\mathbf{P P t}_{2}\right)$, $640 \mathrm{~nm}\left(\mathbf{P P t}_{3}\right)$.

a broad NIR energy regime. At early time delays, the NIR

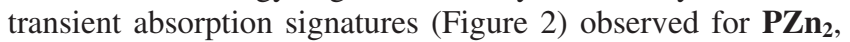
$\mathbf{P P d}_{2}$, and $\mathbf{P P t}_{2}$ are dominated by respective absorption bands centered at $980 \mathrm{~nm}$ (full width at half-maximum $(\mathrm{fwhm})=660$ $\left.\mathrm{cm}^{-1}\right), 888 \mathrm{~nm}\left(\mathrm{fwhm}=930 \mathrm{~cm}^{-1}\right)$, and $848 \mathrm{~nm}(\mathrm{fwhm}=1580$ $\mathrm{cm}^{-1}$ ). The early time-delay transient spectrum of $\mathbf{P Z n _ { 3 }}$ (Figure $3 A)$ exhibits a NIR absorption band $\left(\lambda_{\max }\left(\mathrm{S}_{1} \rightarrow \mathrm{S}_{n}\right)\right)$ centered at $1120 \mathrm{~nm}$; note that this transition is considerably broader ( $f w h m=750 \mathrm{~cm}^{-1}$ ) than that observed for the analogous early time $\mathbf{P Z n} \mathbf{n}_{2}$ NIR transient (fwhm $=670 \mathrm{~cm}^{-1}$ ), and that the $\mathbf{P Z n}_{3}$ $\mathrm{S}_{1} \rightarrow \mathrm{S}_{n}$ spectra also feature a higher energy NIR absorption centered manifold at $\sim 980 \mathrm{~nm}$. In contrast, for $\mathbf{P P d}_{3}$ and $\mathbf{P P t}_{3}$ the low energy transient absorption manifolds observed at $t_{\text {delay }}$ $<350$ fs are significantly broader than that evinced for $\mathbf{P Z n _ { 3 }}$. In this regard, note that $\mathbf{P P d} \mathbf{d}_{\mathbf{3}}$ and $\mathbf{P} \mathbf{P t}_{\mathbf{3}}$ feature prominent transient absorption maxima evident at 984 and $\sim 940 \mathrm{~nm}^{85}$ (Figure 3B,C), respectively; while these highest extinction $\mathrm{S}_{1}$ $\rightarrow \mathrm{S}_{n}$ absorption manifolds are considerably blue-shifted relative to that of the $\mathbf{P Z n _ { 3 }}$ benchmark, note that both $\mathbf{P P d} \mathbf{z}_{\mathbf{3}}$ and $\mathbf{P P t} \mathbf{P}_{\mathbf{3}}$ also display absorption manifolds that extend beyond $1100 \mathrm{~nm}$. Factors that contribute to the more complex nature of the early $t_{\text {delay }} \mathbf{P P d} \mathbf{d}_{3}$ and $\mathbf{P P t} \mathbf{}_{3}$ transient absorption spectra likely include the augmented degree of conformational inhomogeneity of these species relative to that demonstrated previously for $\mathbf{P Z n}_{3}$, and $\mathrm{Pd}(\mathrm{II})$ and $\mathrm{Pt}(\mathrm{II}) d$-orbital/porphyrin $\pi^{*}$-orbital mixing that enables spectral contributions from transitions between states that involve spin multiplicities higher than singlet.

Figures $2 \mathrm{~A}$ and $3 \mathrm{~A}$ show that for electronically excited $\mathbf{P Z \mathbf { n } _ { 2 }}$ and $\mathbf{P Z n}_{3}$, the $S_{1}$ state persists for several hundred picoseconds; ${ }^{86}$ after this time, ground-state bleaching and $\mathrm{S}_{1} \rightarrow \mathrm{S}_{n}$ excitedstate absorption manifold intensities greatly diminish, and weak absorption bands evolve at significantly lower energies $\left(\mathbf{P Z n}_{2}\right.$, $1017 \mathrm{~nm} ; \mathbf{P Z n}_{3}, 1196 \mathrm{~nm}$ ) than those of the $S_{1} \rightarrow S_{n}$ peak maxima. The formation of these new NIR absorptive features is accompanied by the disappearance of the stimulated emission contributions to the respective bleaching signals for these $\mathbf{P} \mathbf{Z} \mathbf{n}_{n}$ species, which contribute significantly to the observed bleach intensity at early time delays. As a result of these considerations, the long-wavelength $\mathbf{P Z \mathbf { n } _ { n }}$ transient absorption bands observed at $t_{\text {delay }}>\sim 100 \mathrm{ps}$ are assigned to transitions between excited triplet states; however, the weak intensity of these $\mathrm{T}_{1} \rightarrow \mathrm{T}_{n}$ transitions, coupled with the near-total loss of the ground-state bleaching signatures at delay times where the $\mathrm{T}_{1} \rightarrow \mathrm{T}_{n}$ transitions are manifested, indicate that population of the triplet surface is a minor deactivation pathway for ${ }^{1} \mathbf{P} \mathbf{Z} \mathbf{n}_{n}{ }^{*}$ species. This conclusion is congruent with related dynamical data that demonstrate that the primary deactivation modes for these ${ }^{1} \mathbf{P Z n}{ }_{n} *$ chromophores are $\mathrm{S}_{1} \rightarrow \mathrm{S}_{0}$ internal conversion and fluorescence, and steady-state experiments that show that these NIR fluorophores manifest unusually high fluorescence quantum yields. ${ }^{54}$ 
TABLE 1: Steady-State Spectroscopic Data of Zinc, Palladium, and Platinum Oligomeric Porphyrin Arrays

\begin{tabular}{llclc}
\hline & $\begin{array}{c}\lambda_{\max } \mathrm{S}_{0} \rightarrow \mathrm{S}_{1}[\mathrm{~nm}]^{a, b} \\
\left(\mathrm{fwhm}, \mathrm{cm}^{-1}\right)\end{array}$ & $\begin{array}{c}\varepsilon_{\mathrm{g}} @ \mathrm{~S}_{0} \rightarrow \mathrm{S}_{1} \\
{\left[\mathrm{M}^{-1} \mathrm{~cm}^{-1}\right]^{a}}\end{array}$ & $\begin{array}{c}\lambda_{\max } \mathrm{S}_{0} \rightarrow \mathrm{S}_{1}[\mathrm{~nm}]^{c, d} \\
\left(\text { Stokes shift, } \mathrm{cm}^{-1}\right)\end{array}$ & $\begin{array}{c}\lambda_{\max } \mathrm{T}_{1} \rightarrow \mathrm{S}_{0}[\mathrm{~nm}]^{c, e} \\
\left(\mathrm{~S}_{0} \rightarrow \mathrm{S}_{1}-\mathrm{T}_{1} \rightarrow \mathrm{S}_{0}, \mathrm{~cm}^{-1}\right)\end{array}$ \\
\hline $\mathbf{P Z n}_{2}{ }^{f}$ & $695(\Delta v=1090)$ & 51400 & $711\left(\Delta v_{\text {Stokes }}=320\right)$ & $g$ \\
$\mathbf{P P d}_{2}$ & $620(\Delta v=1330)$ & 23540 & $h$ & $796(\Delta v=3570)$ \\
$\mathbf{P P t}_{2}$ & $592(\Delta v=\sim 1030)$ & 28510 & $h$ & $750(\Delta v=3600)$ \\
$\mathbf{P Z n}_{3}{ }^{f}$ & $770(\Delta v=1380)$ & 116000 & $806\left(\Delta v_{\text {Stokes }}=580\right)$ & $g$ \\
$\mathbf{P P d}_{3}$ & $666(\Delta v=2170)$ & 50100 & $747\left(\Delta v_{\text {Stokes }}=1790\right)$ & $828(\Delta v=3120)$ \\
$\mathbf{P P t}_{3}$ & $634(\Delta v=1700)$ & 65050 & $\sim 740\left(\Delta v_{\text {Stokes }}=2220\right)$ & $800(\Delta v=3260)$
\end{tabular}

${ }^{a}$ Electronic absorption data were recorded in THF at room temperature. ${ }^{b}$ The parenthetical value is the transition manifold spectral breadth (fwhm) in $\mathrm{cm}^{-1}$. ${ }^{c}$ Emission data were recorded in glassy MTHF at $77 \mathrm{~K}$. ${ }^{d}$ The parenthetical value corresponds to the magnitude of the fluorescence Stokes shift. ${ }^{e}$ The parenthetical values correspond to the energy gap between the $S_{0} \rightarrow S_{1}$ absorption and phosphorescence band maxima, in $\mathrm{cm}^{-1}$. ${ }^{f}$ Spectroscopic data for $\mathbf{P Z n _ { 2 }}$ and $\mathbf{P Z Z n _ { 3 }}$ were taken from cited references. ${ }^{54,63,66}{ }^{g}$ No phosphorescence was observed. ${ }^{h}$ No fluorescence was observed.

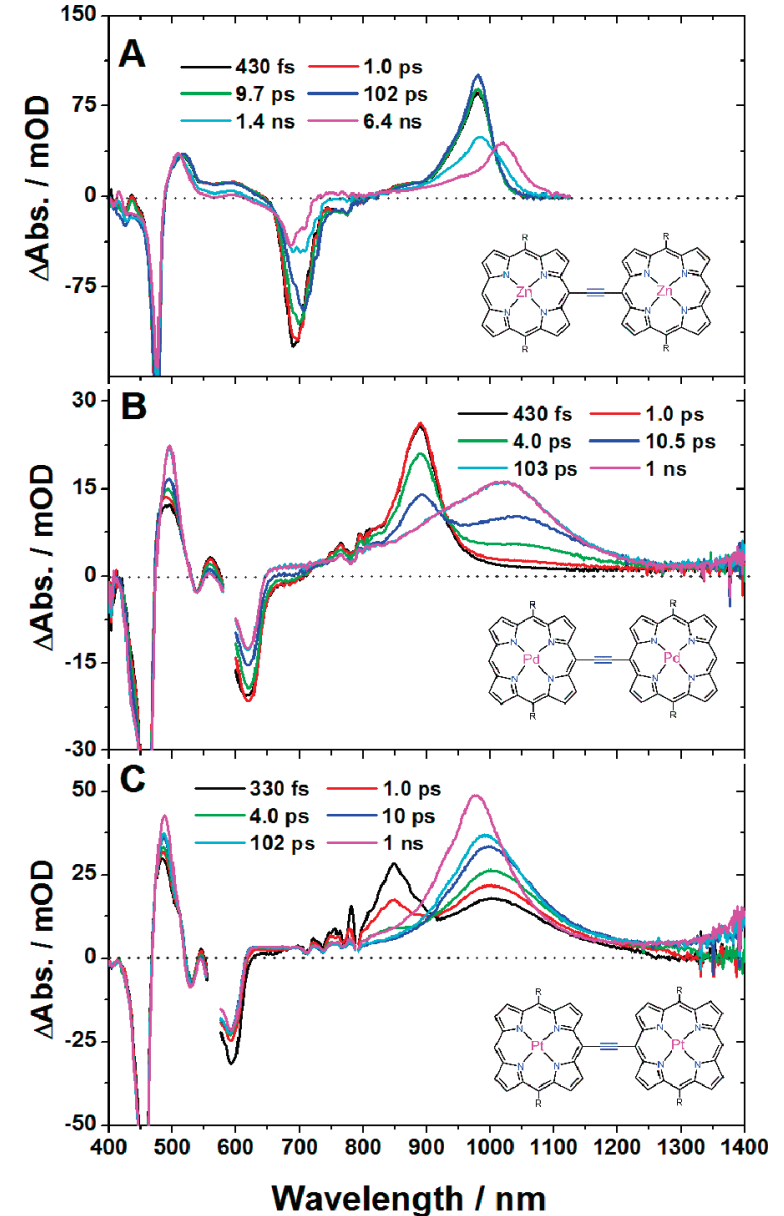

Figure 2. Magic angle transient absorption spectra recorded at selected delay times for (A) $\mathbf{P Z n} \mathbf{n}_{2}$, (B) $\mathbf{P P d}$, and (C) $\mathbf{P P t}_{2}$. Experimental conditions: solvent $=\mathrm{THF}$, ambient temperature, $\lambda_{\mathrm{exc}}=(\mathrm{A}) 684 \mathrm{~nm}$, (B) $590 \mathrm{~nm}$, and (C) $560 \mathrm{~nm}$.

Transient spectra of $\mathbf{P P d}$ and $\mathbf{P P t}_{n}$ observed at later time delays $\left(t_{\text {delay }}>4 \mathrm{ps}\right.$, Figures $2 \mathrm{~B}, \mathrm{C}$ and $\left.3 \mathrm{~B}, \mathrm{C}\right)$ differ markedly from those of the $\mathbf{P Z \mathbf { n } _ { n }}$ benchmarks. As observed in the $\mathbf{P Z \mathbf { n } _ { n }}$ transient absorption data, the excited-state spectra of $\mathbf{P P d}_{n}$ and $\mathbf{P P t}_{n}$ also evolve at long time-delays to give rise to new transient absorption features that lie $150-200 \mathrm{~nm}$ to the red of the $S_{1} \rightarrow$ $\mathrm{S}_{n}$ excited-state absorptions. These transient absorption manifolds that persist through the microsecond time domain are likewise assigned to transitions between states of high spin multiplicity $\left(\mathrm{T}_{1} \rightarrow \mathrm{T}_{n}\right)$. Unlike the $\mathrm{T}_{1} \rightarrow \mathrm{T}_{n}$ transition manifold observed for ${ }^{3} \mathbf{P Z} \mathbf{n}_{n}$ *, the $\mathrm{T}_{1} \rightarrow \mathrm{T}_{n}$ absorption features for both $\mathbf{P P d}_{n}$ and $\mathbf{P P t}_{n}$ are intense and span a broad spectral domain: for example, ${ }^{3} \mathbf{P P d}_{\mathbf{3}} *$ displays a $\mathrm{T}_{1} \rightarrow \mathrm{T}_{n}$ absorption manifold

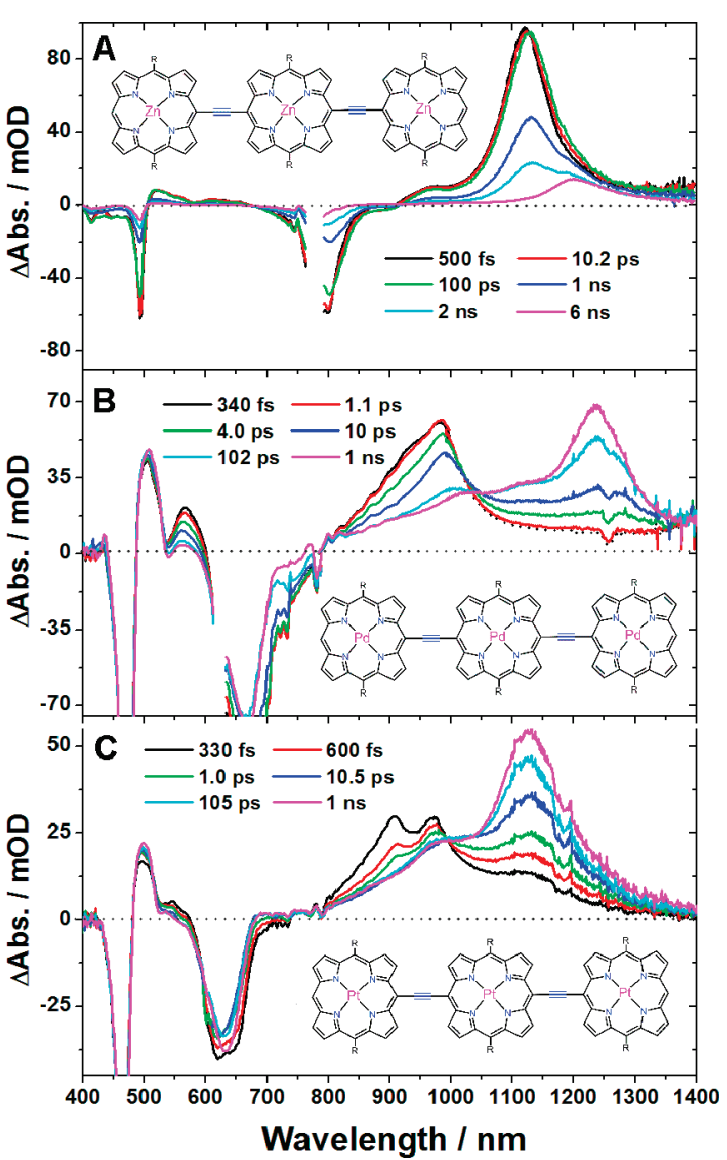

Figure 3. Magic angle transient absorption spectra recorded at selected delay times for (A) $\mathbf{P Z n} \mathbf{n}_{\mathbf{3}}$, (B) $\mathbf{P} \mathbf{P d}_{3}$, and (C) $\mathbf{P P t}_{\mathbf{3}}$. Experimental conditions: solvent $=\mathrm{THF}$, ambient temperature, $\lambda_{\mathrm{exc}}=(\mathrm{A}) 775 \mathrm{~nm}$, (B) $620 \mathrm{~nm}$, and (C) $600 \mathrm{~nm}$.

centered at $1235 \mathrm{~nm}$ having a fwhm of $\sim 2400 \mathrm{~cm}^{-1}$ (Figures 2 and 3; Table 2). It is also noteworthy that the $\mathbf{P P d}$ and $\mathbf{P P t}$ transient spectra evince ground-state bleaching signatures that remain intense at all delay times (Figures 2-3), even after formation of the excited triplet state is complete ( $t_{\text {delay }} \sim 6 \mathrm{~ns}$ ); these data contrast the analogous pump-probe spectroscopic results obtained for $\mathbf{P Z Z} \mathbf{n}_{n}$ species, and show that $\mathrm{T}_{1}$-state formation occurs at near-unit quantum yield.

By monitoring the intensification of the $\mathbf{P P d}$ and $\mathbf{P P t} \mathbf{t}_{n}\left(\mathrm{~T}_{1}\right.$ $\rightarrow \mathrm{T}_{n}$ ) transient absorption bands as a function of time delay, the ISC time scales are easily determined; the corresponding exponential time constants $\left(\tau_{\text {ISC }}\right)$ are compiled in Table 2 . ISC rates scale inversely with the nuclear charge $(Z)$ of the central metal, with $\tau_{\text {ISC }}(\mathrm{Zn})>\tau_{\text {ISC }}(\mathrm{Pd})>\tau_{\text {ISC }}(\mathrm{Pt})$, consistent with the relative magnitudes of the respective spin-orbit coupling 
TABLE 2: Excited-State Spectroscopic Data of Zinc, Palladium, and Platinum Oligomeric Porphyrin Arrays in THF Solvent at Room Temperature

\begin{tabular}{|c|c|c|c|c|c|}
\hline & $\begin{array}{c}\lambda_{\max } \mathrm{S}_{1} \rightarrow \mathrm{S}_{n}[\mathrm{~nm}]^{a} \\
\quad\left(\mathrm{fwhm}, \mathrm{cm}^{-1}\right)\end{array}$ & $\begin{array}{l}\lambda_{\max } \mathrm{T}_{1} \rightarrow \mathrm{T}_{n}[\mathrm{~nm}]^{a} \\
\quad\left(\mathrm{fwhm}, \mathrm{cm}^{-1}\right)\end{array}$ & $\begin{array}{c}\varepsilon_{\mathrm{e}} @ \mathrm{~T}_{1} \rightarrow \mathrm{T}_{n} \\
{\left[\mathrm{M}^{-1} \mathrm{~cm}^{-1}\right]^{b}}\end{array}$ & $\tau_{\text {isc }}[\mathrm{ps}]$ & $\tau_{\mathrm{T}}[\mu \mathrm{s}]$ \\
\hline $\mathbf{P Z n}_{2}^{c}$ & $980(670)$ & $1017(630)$ & $\mathrm{n} / \mathrm{a}$ & $\sim 7500$ & $\mathrm{n} / \mathrm{a}$ \\
\hline $\mathbf{P P d}_{2}$ & $888(930)$ & $1023(2400)$ & $\sim 31000$ & 8.6 & 49.4 \\
\hline $\mathbf{P P t}_{2}$ & $848(1580)$ & $976(1280)$ & $\sim 71000$ & $\sim 0.3$ & 8.4 \\
\hline $\mathbf{P Z \mathbf { n } _ { 3 }}{ }^{c}$ & $1120(750)$ & $1196(820)$ & $\mathrm{n} / \mathrm{a}$ & $>2000^{d}$ & $\mathrm{n} / \mathrm{a}$ \\
\hline $\mathbf{P P d}_{3}$ & $984\left(>5000^{e}\right)$ & $1235(1180)$ & $\sim 45000$ & 52.0 & 33.3 \\
\hline $\mathbf{P P t}_{3}$ & $906,972\left(>5000^{e}\right)$ & $1124(1230)$ & $\sim 95000$ & $\sim 0.6$ & 5.2 \\
\hline
\end{tabular}

${ }^{a}$ The parenthetical value is the spectral breadth $(\mathrm{fwhm})$ in $\mathrm{cm}^{-1} \cdot{ }^{b}$ Excited triplet-state extinction coefficients were determined from the ultrafast transient absorption data at $t_{\text {delay }}=1 \mathrm{~ns}$ by a method discussed elsewhere, ${ }^{52}$ values for $\mathbf{P Z \mathbf { Z }} \mathbf{n}_{\mathbf{2}}$ and $\mathbf{P Z \mathbf { Z }} \mathbf{n}_{\mathbf{3}}$ were not calculated due to the facts that the $\mathrm{T}_{1} \rightarrow \mathrm{T}_{n}$ transition intensity is weak, and the stimulated emission signal contaminates the Q-band bleaching signal even at a 1 ns time delay. ${ }^{c}$ Spectroscopic data for $\mathbf{P Z n _ { 2 }}$ and $\mathbf{P Z \mathbf { n } _ { 3 }}$ were taken from the cited references. ${ }^{58,66,72 ~} d$ There is large uncertainty for $\tau_{\text {isc }}$ for $\mathbf{P Z Z} \mathbf{n}_{\mathbf{3}}$ due to overlap of the excited-state singlet and triplet absorption features and a low ISC quantum yield; ${ }^{54}$ thus a lower limit for this value is reported. ${ }^{e}$ The $\mathrm{S}_{1} \rightarrow \mathrm{S}_{n}$ transition manifolds of $\mathrm{PPd}_{3}$ and $\mathrm{PPt}_{3}$ encompass multiple distinct peak maxima extending over a large portion of the measured NIR spectral window.

constants of these metal ions. ISC rates for $\mathbf{P} \mathbf{P d}_{\mathbf{3}}$ and $\mathbf{P} \mathbf{P t} \mathbf{t}_{\mathbf{3}}$ are slower than those for the corresponding $\mathbf{P P d} \mathbf{d}_{2}$ and $\mathbf{P} \mathbf{P t}_{\mathbf{2}}$ species, indicating that $\mathrm{S}_{1}$-to- $\mathrm{T}_{1}$ conversion rate constants may continue to diminish with increasing conjugation length. This effect has been verified in benchmark $\mathbf{P Z} \mathbf{n}_{n}$ compounds as a function of conjugation length; for example, the measured ISC rate for $\mathbf{P Z \mathbf { n } _ { 5 }}$ is so small relative to the corresponding radiative and internal conversion rate constants that its excited triplet state remains virtually unpopulated following $\mathrm{S}_{0} \rightarrow \mathrm{S}_{1}$ excitation. ${ }^{54}$ Because the heavy-atom-derived ISC rates in $\mathbf{P P d}$ and $\mathbf{P} \mathbf{P t} \mathbf{t}_{n}$ species are much faster than the intrinsic ${ }^{59,66,87,88}$ porphyrin nonradiative decay processes, ISC quantum yields approach unity, even for the $\mathbf{P P d} \mathbf{d}_{\mathbf{3}}$ and $\mathbf{P P t}_{\mathbf{3}}$ derivatives; $\mathrm{T}_{1} \rightarrow \mathrm{T}_{n}$ excited-state absorptions are intense in comparison to those of their $\mathbf{P Z \mathbf { n } _ { n }}$ analogs at 500 ps $<t_{\text {delay }}<50 \mu \mathrm{s}$. As a result, the molar absorptivities of the $\mathbf{P P d}{ }_{n}$ and $\mathbf{P P t} t_{n}$ excited triplet states are universally large, as indicated by the $\mathrm{T}_{1} \rightarrow \mathrm{T}_{n}$ molar extinction coefficients compiled in Table 1. The value of $\varepsilon_{\mathrm{e}}(\lambda=1124 \mathrm{~nm}) \sim 95000 \mathrm{M}^{-1} \mathrm{~cm}^{-1}$ at $t_{\text {delay }}=1 \mathrm{~ns}$ for $\mathbf{P P t}_{\mathbf{3}}$ (Figure 3C) indicates that this compound is one of the most intensely absorbing excited triplet states reported to date in the NIR energy regime.

Anaerobic transient absorption experiments carried out over a nanosecond-microsecond time scale were utilized to determine the lifetimes of the $\mathbf{P} \mathbf{P d} \mathbf{d}_{n}$ and $\mathbf{P P t} \mathbf{t}_{n}$ excited triplet states $\left(\tau_{\mathrm{T}}\right)$ described above (Table 1; spectral data are displayed in the Supporting Information, Figures S1-S4). While the triplet lifetimes of these compounds all exceed $5 \mu \mathrm{s}$, the data show that $\tau_{\mathrm{T}}\left(\mathbf{P P d} \mathbf{d}_{n}\right)$ is generally longer than the analogous $\tau_{\mathrm{T}}\left(\mathbf{P P t} \mathbf{t}_{n}\right)$ value, reflecting the trend in the $\tau_{\text {ISC }}$ values noted above. While the lifetimes of the $\mathbf{P P d} \mathbf{d}_{\mathbf{3}}$ and $\mathbf{P} \mathbf{P t}_{\mathbf{3}}$ are shorter than their $\mathbf{P P d}$ and $\mathbf{P} \mathbf{P t}_{\mathbf{2}}$ counterparts in agreement with the energy gap law, ${ }^{49,89}$ it is important to underscore that the extent to which $\tau_{\mathrm{T}}$ diminishes with increasing conjugation length is modest for a given metal ion: it is anticipated that $\mathbf{P P d}$ and $\mathbf{P P t} \mathbf{p}_{\boldsymbol{n}}$ species having longer conjugation lengths will afford further modulation of the OPL window while maintaining $\mathrm{T}_{1}$ states having microsecond lifetimes.

Carrying out similar pump-probe experiments under aerobic conditions results in efficient excited-state quenching (complete ground-state recovery within $1 \mu \mathrm{s}$ ), as expected for states with high spin multiplicity. ${ }^{51}$ It is noteworthy that these $\mathbf{P P d}$ and $\mathbf{P P t}_{n} \mathrm{~T}_{1}$ lifetimes are comparable to or exceed the triplet-state lifetimes of a variety of metal(II) naphthalocyanines that are currently being utilized for OPL applications in the visible regime. ${ }^{7}$

\section{Conclusion}

In conclusion, we have demonstrated that coupled oscillator photophysics can be exploited to fabricate supermolecular chromophores that possess intense excited-state absorption bands over broad spectral regions of the NIR. In these systems, the large spin-orbit coupling has been utilized to drive nearquantitative yield of the electronically excited triplet states of $\mathbf{P P d} \mathbf{d}_{n}$ and $\mathbf{P P t}{ }_{n}$ species, which possess spectacular, intense, broad absorptivity over technologically important spectral domains of the NIR. While intense NIR excited-state absorption features in heavy-metal containing multimeric porphyrin complexes have been reported before, ${ }^{47,52,53}$ it is clear that $\mathbf{P P d} \mathbf{P d}_{\boldsymbol{n}}$ and $\mathbf{P} \mathbf{P t}_{\boldsymbol{n}}$ structures offer unique flexibility with respect to tuning the position of maximum excited-state absorptivity while assuring microsecond $\mathrm{T}_{1}$-state lifetimes. For sequential one-photon absorptive processes, $\mathbf{P} \mathbf{P d}_{\mathbf{2}}, \mathbf{P} \mathbf{P t}_{\mathbf{2}}, \mathbf{P} \mathbf{P d}_{\mathbf{3}}$, and $\mathbf{P} \mathbf{P t}_{\mathbf{3}}$ chromophores evince enormous excited-state absorptive extinction coefficients (30 000-100 $000 \mathrm{M}^{-1} \mathrm{~cm}^{-1}$ ) at $\lambda_{\max }$ values that range from 970 to $1235 \mathrm{~nm}$. Given that the lifetimes of these species range from 5 to $50 \mu \mathrm{s}$, coupled with the fact the full widths at half-maximum of their $\mathrm{T}_{1} \rightarrow \mathrm{T}_{n}$ absorptive manifolds span 1200-2400 $\mathrm{cm}^{-1}$, $\mathbf{P P d}_{n}$ and $\mathbf{P P t}{ }_{n}$ structures define a new precedent for conjugated materials that feature low-lying electronically excited states that are purely $\pi-\pi^{*}$ in nature for NIR optical limiting and related long-wavelength NLO applications.

Acknowledgment. This work was supported by a grant from the Department of Energy (DE-SC0001517). We thank the NSF MRSEC (DMR0520020) and DOE EFRC (P353-0127) programs for infrastructural support. T.V.D. acknowledges a Carolyn Hoff Lynch Graduate Fellowship, and M.J.T. is grateful to the Francqui Foundation (Belgium) and VLAC (Vlaams Academisch Centrum), Centre for Advanced Studies of the Royal Flemish Academy of Belgium for Science and the Arts, for research fellowships. We also thank Patrick J. Carroll at the University of Pennsylvania X-ray Crystallography Facility for solving the $\mathbf{P} \mathbf{P d}_{\mathbf{2}}$ and $\mathbf{P} \mathbf{P t}_{\mathbf{2}}$ structures.

Supporting Information Available: Synthetic and characterization details; X-ray crystallographic data for $\mathbf{P P d}$ and $\mathbf{P P t}$; microsecond time domain transient absorption data. This material is available free of charge via the Internet at http:// pubs.acs.org.

\section{References and Notes} 338.

(1) Tutt, L. W.; Boggess, T. F. Prog. Quant. Electron. 1993, 17, 299- 
(2) Wang, J.; Blau, W. J. J. Opt. A. Pure Appl. Opt. 2009, 11, 024001/ $1-024001 / 16$.

(3) Shirk, J. S.; Pong, R. G. S.; Bartoli, F. J.; Snow, A. W. Appl. Phys. Lett. 1993, 63, 1880-1882.

(4) Perry, J. W.; Mansour, K.; Lee, I.-Y. S.; Wu, X.-L.; Bedworth, P. V.; Chen, C.-T.; Ng, D.; Marder, S. R.; Miles, P.; Wada, T.; Tian, M.; Sasabe, H. Science 1996, 273, 1533-1536.

(5) de la Torre, G.; Vázquez, P.; Agulló-López, F.; Torres, T. Chem. Rev. 2004, 104, 3723-3750.

(6) Nitschke, C.; O'Flaherty, S. M.; Kröll, M.; Blau, W. J. J. Phys. Chem. B 2004, 108, 1287-1295.

(7) Chen, Y.; Hanack, M.; Araki, Y.; Ito, O. Chem. Soc. Rev. 2005 34, 517-529.

(8) Dini, D.; Calvete, M. J. F.; Hanack, M.; Meneghetti, M. J. Phys. Chem. A 2008, 112, 8515-8522.

(9) Zhang, L.; Wang, L. J. Mater. Sci. 2008, 43, 5692-5701

(10) Chen, Y.; Gao, L.; Feng, M.; Gu, L.; He, N.; Wang, J.; Araki, Y.; Blau, W. J.; Ito, O. Mini-Rev. Org. Chem. 2009, 6, 55-65.

(11) Manaa, H.; Al Mulla, A.; Makhseed, S.; Al-sawah, M.; Samuel, J. Opt. Mater. 2009, 32, 108-114.

(12) Chen, P.; Tomov, I. V.; Dvornikov, A. S.; Nakashima, M.; Roach, J. F.; Alabran, D. M.; Rentzepis, P. M. J. Phys. Chem. 1996, 100, $17507-$ 17512.

(13) Su, W.; Cooper, T. M.; Brant, M. C. Chem. Mater. 1998, 10, 1212 1213 .

(14) Pandey, R. K.; Sandeep, C. S. S.; Philip, R.; Lakshminarayanan, V. J. Phys. Chem. C 2009, 113, 8630-8634.

(15) Tutt, L. W.; Kost, A. Nature 1992, 356, 225-226.

(16) Brusatin, G.; Signorini, R. J. Mater. Chem. 2002, 12, 1964-1977.

(17) Goh, H.-W.; Goh, S. H.; Xu, G. Q.; Lee, K. Y.; Yang, G. Y.; Lee,

Y. W.; Zhang, W.-D. J. Phys. Chem. B 2003, 107, 6056-6062.

(18) Iliopoulos, K.; Couris, S.; Hartnagel, U.; Hirsch, A. Chem. Phys. Lett. 2007, 448, 243-247.

(19) Mountrichas, G.; Pispas, S.; Xenogiannopoulou, E.; Aloukos, P.; Couris, S. J. Phys. Chem. B 2007, 111, 4315-4319.

(20) Ouyang, X.; Zeng, H.; Ji, W. J. Phys. Chem. B 2009, 113, 1456514573 .

(21) Chin, K. C.; Gohel, A.; Chen, W. Z.; Elim, H. I.; Ji, W.; Chong, G. L.; Sow, C. H.; Wee, A. T. S. Chem. Phys. Lett. 2005, 409, 85-88.

(22) Chen, Y.; Lin, Y.; Liu, Y.; Doyle, J.; He, N.; Zhuang, X.; Bai, J.;

Blau, W. J. J. Nanosci. Nanotechnol. 2007, 7, 1268-1283.

(23) Chen, Y.; Muthukumar, V. S.; Wang, Y.; Li, C.; Krishnan, S. S.; Sai, S. S. S.; Venkataramaniah, K.; Mitra, S. J. Mater. Chem. 2009, 19, 6568-6572.

(24) Wang, J.; Chen, Y.; Blau, W. J. Mater. Chem. 2009, 19, 74257443

(25) Zhang, L.; Allen, S. D.; Woelfle, C.; Zhang, F. J. J. Phys. Chem.

C 2009, 113, 13979-13984.

(26) Wang, G.; Sun, W. J. Phys. Chem. B 2006, 110, 20901-20905.

(27) Venkatram, N.; Kumar, R. S. S.; Rao, D. N. J. Appl. Phys. 2006, 100, 074309/1-8.

(28) Martin, R. B.; Meziani, M. J.; Pathak, P.; Riggs, J. E.; Cook, D. E.; Perera, S.; Sun, Y.-P. Opt. Mater. 2007, 29, 788-793.

(29) Yu, X.-L.; Cao, C.-B.; Zhu, H.-S.; Li, Q.-S.; Liu, C.-L.; Gong, Q.-H. Adv. Funct. Mater. 2007, 17, 1397-1401.

(30) Zhu, J. Appl. Opt. 2008, 47, 5848-5852.

(31) Li, Q.; Liu, C.; Zang, L.; Gong, Q.; Yu, X.; Cao, C. J. Opt. Soc. Am. B-Opt. Phys. 2008, 25, 1978-1983.

(32) Singh, C. P.; Bindra, K. S.; Bhalerao, G. M.; Oak, S. M. Opt. Exp. 2008, 16, 8440-8450.

(33) Patra, A.; Venkatram, N.; Rao, D. N.; Radhakrishnan, T. P. J. Phys. Chem. C 2008, 112, 16269-16274.

(34) Polavarapu, L.; Venkatram, N.; Ji, W.; Xu, Q.-H. ACS Appl. Mater. Int. 2009, 1, 2298-2303.

(35) Pan, H.; Chen, W.; Feng, Y. P.; Ji, W.; Lin, J. Appl. Phys. Lett. 2006, 88, 223106/1-3.

(36) Zhou, G.-J.; Wong, W.-Y.; Lin, Z.; Ye, C. Angew. Chem., Int. Ed. 2006, 45, 6189-6193.

(37) Zhou, G.-J.; Wong, W.-Y.; Ye, C.; Lin, Z. Adv. Funct. Mater. 2007, 17, 963-975.

(38) Zheng, Q.; Gupta, S. K.; He, G. S.; Tan, L.-S.; Prasad, P. N. Adv. Funct. Mater. 2008, 18, 2770-2779.

(39) Girardot, C.; Cao, B.; Mulatier, J.-C.; Baldeck, P. L.; Chauvin, J.; Riehl, D.; Delaire, J. A.; Andraud, C.; Lemercier, G. Chem. Phys. Chem. 2008, 9, 1531-1535.

(40) Manjunatha, M. G.; Adhikari, A. V.; Hegde, P. K.; Sandeep,

C. S. S.; Philip, R. J. Mater. Sci. 2009, 44, 6069-6077.

(41) Kamanina, N. V.; Voronin, Y. M.; Varnaev, A. V.; Bagrov, I. V.; Zhevlakov, A. P. Synth. Met. 2003, 138, 317-322.

(42) Lin, T.-C.; He, G. S.; Zheng, Q.; Prasad, P. N. J. Mater. Chem. 2006, 16, 2490-2498.
(43) Bouit, P.-A.; Wetzel, G.; Berginc, G.; Loiseaux, B.; Toupet, L.; Feneyrou, P.; Bretonnière, Y.; Kamada, K.; Maury, O.; Andraud, C. Chem. Mater. 2007, 19, 5325-5335.

(44) Li, F.; Zheng, Q.; Yang, G.; Dai, N.; Lu, P. Mater. Lett. 2008, 62, 3059-3062.

(45) Lin, T.-C.; Chen, Y.-F.; Hu, C.-L.; Hsu, C.-S. J. Mater. Chem. 2009, 19, 7075-7080.

(46) Zheng, Q.; He, G. S.; Prasad, P. N. Chem. Phys. Lett. 2009, 475, $250-255$.

(47) Hales, J. M.; Cozzuol, M.; Screen, T. E. O.; Anderson, H. L.; Perry, J. W. Opt. Exp. 2009, 17, 18478-18488.

(48) Bouit, P.-A.; Westlund, R.; Feneyrou, P.; Maury, O.; Malkoch, M.; Malmström, E.; Andraud, C. New J. Chem. 2009, 33, 964-968.

(49) Englman, R.; Jortner, J. Mol. Phys. 1970, 18, 145.

(50) Caspar, J. V.; Meyer, T. J. J. Phys. Chem. 1983, 87, 952-957.

(51) Turro, N. J. Modern Molecular Photochemistry; University Science Books: Sausolito, CA, 1991.

(52) Duncan, T. V.; Rubtsov, I. V.; Uyeda, H. T.; Therien, M. J. J. Am. Chem. Soc. 2004, 126, 9474-9475.

(53) Duncan, T. V.; Ishizuka, T.; Therien, M. J. J. Am. Chem. Soc. 2007, 129, 9691-9703.

(54) Duncan, T. V.; Susumu, K.; Sinks, L. E.; Therien, M. J. J. Am. Chem. Soc. 2006, 128, 9000-9001.

(55) Papp, S.; Vanderkooi, J. M.; Owen, C. S.; Holtom, G. R.; Phillips, C. M. Biophys. J. 1990, 58, 177-186.

(56) Lin, V. S.-Y.; DiMagno, S. G.; Therien, M. J. Science 1994, 264, $1105-1111$.

(57) Lin, V. S.-Y.; Therien, M. J. Chem.-Eur. J. 1995, 1, 645-651.

(58) Angiolillo, P. J.; Lin, V. S.-Y.; Vanderkooi, J. M.; Therien, M. J. J. Am. Chem. Soc. 1995, 117, 12514-12527.

(59) Kumble, R.; Palese, S.; Lin, V. S.-Y.; Therien, M. J.; Hochstrasser,

R. M. J. Am. Chem. Soc. 1998, 120, 11489-11498.

(60) Fletcher, J. T.; Therien, M. J. J. Am. Chem. Soc. 2000, 122, 1239312394.

(61) Shediac, R.; Gray, M. H. B.; Uyeda, H. T.; Johnson, R. C.; Hupp, J. T.; Angiolillo, P. J.; Therien, M. J. J. Am. Chem. Soc. 2000, 122, 70177033

(62) Angiolillo, P. J.; Susumu, K.; Uyeda, H. T.; Lin, V. S.-Y.; Shediac, R.; Therien, M. J. Synth. Met. 2001, 116, 247-253.

(63) Susumu, K.; Therien, M. J. J. Am. Chem. Soc. 2002, 124, 85508552.

(64) Fletcher, J. T.; Therien, M. J. J. Am. Chem. Soc. 2002, 124, 42984311.

(65) Fletcher, J. T.; Therien, M. J. Inorg. Chem. 2002, 41, 331-341.

(66) Rubtsov, I. V.; Susumu, K.; Rubtsov, G. I.; Therien, M. J. J. Am. Chem. Soc. 2003, 125, 2687-2696.

(67) Ostrowski, J. C.; Susumu, K.; Robinson, M. R.; Therien, M. J.; Bazan, G. C. Adv. Mater. 2003, 15, 1296-1300.

(68) Angiolillo, P. J.; Uyeda, H. T.; Duncan, T. V.; Therien, M. J. J. Phys. Chem. B 2004, 108, 11893-11903.

(69) Susumu, K.; Duncan, T. V.; Therien, M. J. J. Am. Chem. Soc. 2005, 127, 5186-5195

(70) Ghoroghchian, P. P.; Frail, P. R.; Susumu, K.; Blessington, D.; Brannan, A. K.; Bates, F. S.; Chance, B.; Hammer, D. A.; Therien, M. J. Proc. Natl. Acad. Sci. U.S.A. 2005, 102, 2922-2927.

(71) Ghoroghchian, P. P.; Frail, P. R.; Susumu, K.; Park, T.-H.; Wu, S. P.; Uyeda, H. T.; Hammer, D. A.; Therien, M. J. J. Am. Chem. Soc. 2005, 127, 15388-15390.

(72) Duncan, T. V.; Wu, S. P.; Therien, M. J. J. Am. Chem. Soc. 2006, 128, 10423-10435

(73) Susumu, K.; Frail, P. R.; Angiolillo, P. J.; Therien, M. J. J. Am. Chem. Soc. 2006, 128, 8380-8381.

(74) Frail, P. R.; Susumu, K.; Huynh, M.; Fong, J.; Kikkawa, J. M.; Therien, M. J. Chem. Mater. 2007, 19, 6062-6064.

(75) Keinan, S.; Therien, M. J.; Beratan, D. N.; Yang, W. T. J. Phys. Chem. A 2008, 112, 12203-12207.

(76) Duncan, T. V.; Ghoroghchian, P. P.; Rubtsov, I. V.; Hammer, D. A.; Therien, M. J. J. Am. Chem. Soc. 2008, 130, 9773-9784.

(77) Duncan, T. V.; Song, K.; Hung, S. T.; Miloradovic, I.; Nayak, A.; Persoons, A.; Verbiest, T.; Therien, M. J.; Clays, K. Angew. Chem., Int. Ed. 2008, 47, 2978-2981.

(78) Fisher, J. A. N.; Susumu, K.; Therien, M. J.; Yodh, A. G. J. Chem. Phys. 2009, 130, 134506/1-8.

(79) Banerjee, P.; Conklin, D.; Nanayakkara, S.; Park, T.-H.; Therien, M. J.; Bonnell, D. A. ACS Nano 2010, 4, 1019-1025.

(80) DiMagno, S. G.; Lin, V. S.-Y.; Therien, M. J. J. Org. Chem. 1993, 58, 5983-5993.

(81) DiMagno, S. G.; Lin, V. S.-Y.; Therien, M. J. J. Am. Chem. Soc. 1993, 115, 2513-2515.

(82) Eastwood, D.; Gouterman, M. J. Mol. Spectrosc. 1970, 35, 359.

(83) Optical Spectra and Electronic Structure of Porphyrins; Gouterman, M., Ed.; Academic Press: New York, 1978; Vol. 3. 
(84) Harriman, A. J. Chem. Soc., Faraday Trans. 2 1981, 77, 12811291.

(85) The $S_{1} \rightarrow S_{n}$ transition manifold exhibits two well-resolved transitions of nearly equal intensity (Table 2); $940 \mathrm{~nm}$ represents an average position.

(86) There are some moderate-scale excitation-wavelength-dependent changes to the spectral features that occur on a $15-30$ ps time scale. These changes are generally associated with structural relaxation around the ethyne bridge, with excited electronic-state conformeric populations favoring smaller average macrocycle-macrocycle dihedral angles than those of the ground electronic state.

(87) Baskin, J. S.; Yu, H.-Z.; Zewail, A. H. J. Phys. Chem. A 2002, 106, 9837-9844.

(88) Wynne, K.; LeCours, S. M.; Galli, C.; Therien, M. J.; Hochstrasser, R. M. J. Am. Chem. Soc. 1995, 117, 3749-3753.

(89) Caspar, J. V.; Meyer, T. J. J. Phys. Chem. 1983, 87, 952-957.

JP102901U 